\title{
REVIEW
}

\section{The Challenge of Pathological Diagnosis for Precancerous Cervical Lesions}

\author{
İlkay Çinar ${ }^{1}$ \\ ${ }^{1}$ Giresun University Prof. Dr. A. İlhan Özdemir Research and Training Hospital Department of Pathology, Giresun, Turkey
}

Received: 02 February 2019, Accepted: 22 February 2019, Published online: 28 April 2019

(C) Ordu University Institute of Health Sciences, Turkey, 2019

\begin{abstract}
Cervical cancer is the third most common cancer after breast and colorectal cancers worldwide, and the second most common gynecological malignancy after endometrial cancer. Cervical cancer screening was first described by Papanicolaou in 1941 using the PAP smear test. The incidence of invasive cervical cancer clearly reduced with the common use of PAP smear in developed countries. The basic methods used for diagnosis of premalignant lesions of the cervix are determination with colposcopy, biopsy and HPV DNA typing. Cervical premalignant lesions cannot be observed with the naked eye, other than exophytic or papillary lesions of condyloma acuminatum. Condyloma acuminatum are simultaneously LSIL. LSIL and HSIL differentiation cannot be made with colposcopy. Due to better repeatability and interobserver compliance, the World Health Organization (WHO) recommends a 2-layer HSIL/LSIL system. In the 3-layer CIN system, CIN1 is equivalent to LSIL, while CIN3 equivalent is HSIL. The lesions are frequently encountered in routine biopsies, and in some cases, differential diagnosis may be difficult. Basal cell hyperplasia, atrophy, reactive and repair-induced atypia and immature squamous metaplasia may mimic precancerous lesions. Although histomorphology is gold standard, P16 and Ki-67 are beneficial immunohistochemical ancillary testes. However, it should be kept in mind that p16 can be positive in LSIL, and negative in HSIL.

Key words: Cervix, premalignant lesions, pathology
\end{abstract}

Suggested Citation: Çınar I. The Challenge of Pathological Diagnosis for Precancerous Cervical Lesions. Middle Black Sea Journal of Health Science 2019; 5(1): 39-44

Address for correspondence/reprints:

İlkay Çinar

Telephone number: +90(532) 7981696

E-mail: a.ilkaycinar@gmail.com

DOI: $10.19127 / \mathrm{mbsjohs.521193}$

\section{Introduction}

Cervical cancer is observed in $3^{\text {rd }}$ place after breast and colorectal cancers in the world in general and is the $2^{\text {nd }}$ most common gynecological malignancy after endometrial cancer (Eser, 2010). In countries around the world, cervical cancer comprises nearly $12 \%$ of all cancers in women (Ferlay et al., 2015). In Turkey according to Ministry of Health Turkish Public Health Organization data, this rate is $2.7 \%$ (Sencan I et al., 2014). For more than $90 \%$ of cervical cancer and cervical intraepithelial neoplasia (CIN) cases, the main factor in development of cancer is human papilloma virus (HPV) (Walboomers et al., 1999).

Precancerous lesions of the cervix are named CIN1/CIN2/CIN3 linked to the degree of effect on 
the epithelium. CIN1 is also known as low grade intraepithelial lesion (LSIL), while CIN2 and CIN3 are known as high-grade intraepithelial lesion (HSIL). Lesions beginning as CIN1 may transform to CIN2 or may develop "de novo" without progression to CIN2 and CIN3 (Gupta \&Basavaraj, 2018). The progression potential of these types of lesions has been researched in many studies. According to the study by Ostor et al., $60 \%$ of CIN1 lesions regress, $11 \%$ transform to carcinoma in situ (CIS) and only $1 \%$ result in invasive cancer. For CIN2, 40\% regress and 33\% of CIN3 regress. For CIN2, 5\% transform into invasive cancer, while $12 \%$ of CIN3 transform to invasive cancer (Ostor, 1993).

Adenocarsinomas are $2^{\text {nd }}$ most common cervical cancers after squamous cancers. Precursors of adenocancers are adenocarcinoma in situ (AIS) or glandular lesions. Glandular lesions may be multifocal. AIS is associated with HPV at rates of 90\% (Quint et al., 2010).

\section{Screening Method}

Cervical cancer screening was first described by Papanicolaou in 1941 using the PAP smear test. The incidence of invasive cervical cancer clearly reduced with the common use of PAP smear in developed countries, with regression in cervical cancer incidence falling to sixth or even tenth place in some countries (Eser, 2010; Ferlay et al., 2015). According to Republic of Turkey Ministry of Health records, in Turkey cervical cancer incidence is in $9^{\text {th }}$ place (Sencan I et al., 2014). In recent years, the HPV test has been used as a screening method. Although screening test is not suggested before 21 years of age, it is recommended to have a pap smear test every 3 years in the 21-29 age range, and a pap smear test every 3 years or co-test (HPV and PAP smear test combination) every 5 years after the age 30 years old.(Saslow et al., 2012).

The Bethesda system, developed for standardization of PAP smear reports, standardized a diagnostic approach for cervical cytology and was most recently updated in 2014 (Nayar et al., 2015). In this system, cervical epithelial lesions are classified as atypical squamous cells, atypical squamous cells with undetermined significance (ASC-US) and atypical squamous cells not excluding high-grade cervical intraepithelial lesions (ASC-H) (Table 1) (Nayar et al., 2015). ASC-US diagnosis is reported for up to $5 \%$ of cervical smears with low repeatability between pathologists. When these cases are monitored, just as intraepithelial lesions or malignancy may not be encountered, varying rates of CIN may be observed (Edebal et al.,
2017). A study by Katki et al. (2013) identified that patients with ASC-H identified on PAP smear had CIN2 prevalence of $35 \%$, CIN3 prevalence of $18 \%$ and cervical cancer incidence rates of $2.6 \%$ after colposcopy and biopsy.

Table 1. Classification of squamous cell abnormalities with the Bethesda system

\section{SQUAMOUS CELLS}

- Atypical squamous cells

- Undetermined significance (ASC-US)

- Cannot exclude HSIL (ASC-H)

- Low-grade squamous intraepithelial lesion (LSIL) -( HPV/mild dysplasia/CIN1)

- High-grade squamous intraepithelial lesion (HSIL) -(Moderate/severe dysplasia/CIN2/CIN3/CIS)

- Squamous cell carcinoma

\section{Diagnostic methods}

The basic methods used for diagnosis of premalignant lesions of the cervix are determination of cervical lesions with colposcopy, biopsy and HPV DNA typing. Though the Bethesda system was developed for use in description of cervical cytologic samples, it is still used for histologic diagnosis. For biopsy material, the most common classifications are the CIN classification and the Bethesda system (Table 2).

Table 2. Comparison of Bethesda and CIN classifications CIN1: Dysplasia of lower 1/3 of epithelium LSIL

\begin{tabular}{ll}
\hline CIN2: Dysplasia of 2/3 of & HSIL \\
epithelium/koilocytosis & \\
CIN3: Dysplasia of more than 2/3 of \\
epithelium
\end{tabular}

\section{P16}

P16 is a protein coded on the $9^{\text {th }}$ chromosome of the CDKN2A gene in humans, which acts as a G1 control point regulator and cyclin-dependent kinase inhibitor tumor suppressor. It accumulates in the cytoplasm and nuclei of cells infected with HPV and with loss of control of the cell cycle (Wentzensen et al., 2007; Tsoumpou et al. 2009). P16 is used as a sensitive and specific marker for determination of cervical cancer and precursors (Wentzensen et al., 2007; Cuschieri et al., 2008; Gustinucci et al., 2012). The use of P16 and Ki-67 together increases the diagnostic sensitivity (Sun et al., 2018). According to LAST (lower anogenital squamous terminology standardization project) project results, it is recommended that CIN2 showing over expression of P16 should be classified as HSIL and treated accordingly for lesions associated with HPV. If CIN2 lesions do not show P16 
overexpression, they may be assessed as LSIL with low risk of progression (Darragh et al., 2013).

\section{HPV}

HPV infection is shown to be a critical precursor for squamous and adenocancers of the cervix (Moore et al., 2010). HPV transmitted by sexual routes infects the basal layer of the cervical epithelium in the transformation zone. Proliferation of the virus causes changes in the lower $1 / 3$ of the epithelium, enlargement of the nuclei, hyperchromasia and koilocytosis. These changes are named CIN1 or LSIL. Natural immunity clears 90\% of HPV infections and the lesion disappears. In $10 \%$ of infected women, persistent oncogenic HPV infection causes inactivation of tumor-suppressing genes (p53, pRB) due to viral oncoproteins of E6 and E7. Thus, control of the normal cell cycle is lost. Without natural control mechanisms, proliferation of cells causes formation of high- grade lesions (Doorbar et al., 2012).

\section{Terminology}

At the beginning of the $20^{\text {th }}$ century, terms like "surface carcinoma, intraepithelial carcinoma or carcinoma in situ" were used for cells with carcinoma features in situations which had not exceeded the basal membrane. Diagnosis of carcinoma in situ (CIS) determined by 2 clinical approaches. While those without CIS did not require a hysterectomy, those with CIS had hysterectomy performed. After a duration of over 100 years, the basic approaches are still the same. In the 1950s, pathologists defined lesions with less severity than CIS. The term "atypical hyperplasia" described a lesion with less severity than CIS and was later changed to dysplasia. Dysplasia is classified as mild/moderate/severe. While those with CIS diagnosis continue to have hysterectomy performed, severe dysplasia began to be treated with more conservative methods like conization. In 1956 Kos and Durfee defined koilocytes (from the Greek meaning cave). Definition of the association between koilocytes and HPV was made 20 years later. In 1969 Richard revealed the concept that there may be a spectrum in cervical cancer varying from mild dysplasia to CIS. This spectrum determined the CIN term. Mild dysplasia is called CIN1, moderate dysplasia is CIN2 and severe dysplasia is called CIN3. For CIN treatment, hysterectomy is only recommended for women without expectations of child-bearing.

From 1980 to 2000, the development of molecular biology led to an understanding of HPV and cervical carcinogenesis. CIN1/mild dysplasia/koilocytic atypia were defined as histological and cytological equivalents of HPV infection. These lesions have low progression risk, most regress during surveillance and treatment is accepted as clinical observation. Contrary to this, CIN2/CIN3 and CIS are morphological equivalents of cell transformation linked to the HPV oncogene. These lesions have persistent character and have greater tendency toward progression and invasive tumor development. As a result, they are accepted as being high grade. These concepts greatly affected classification of cervical PAP cytology and pioneered the Bethesda system. LSIL and HSIL are terminology recommended for all intraepithelial neoplasia associated with HPV in the lower anogenital region, and not just for CIN (Keating et al., 2001; Lysandra et al., 2016).

\section{Macroscopy}

Cervical premalignant lesions cannot be observed with the naked eye, other than exophytic or papillary lesions of condyloma acuminatum. Condyloma acuminatum are simultaneously LSIL. LSIL and HSIL differentiation cannot be made with colposcopy (Stoler et al., 2014).

\section{Histopathology}

Due to better repeatability and intraobserver compliance, the World Health Organization (WHO) recommends a 2-layer HSIL/LSIL system. In the 3layer CIN system, CIN1 is equivalent to LSIL, while CIN3 equivalent is HSIL. CIN2 is the group with lowest repeatability. For these cases, classification as HSIL or LSIL according to immunohistochemical data is recommended (Stoler et al., 2014).

\section{LSIL}

LSIL is a morphologic sign of HPV virion production in host squamous cells (Stoler, 2000). It is characterized by proliferation of cells in the parabasal/basal-like cells in the lower $1 / 3$ of the epithelium. The normally-observed garden-fence like sequence of basal cells is lost. Mitosis is limited to this area. Koilocytic atypia characterized by increased nucleus/cytoplasm rates, perinuclear halo and grapeseed-like disrupted nuclear contours is typical of LSIL. Koilocytosis is mostly observed in the upper portion of the epithelium. At the surface parakeratosis or hyperkeratosis may be observed (Koss \&Durfee, 1956). Most koilocytosis is observed in HSIL; however, not in all. Histomorphological findings are the gold standard. Immunohistochemistry may be beneficial for cases where definite decision cannot be made. Clear 
atypical cells and atypical mitosis presence does not comply with LSIL. In these situations, it is more appropriate to make HSIL diagnosis. Most LSIL cases regress within 1 year. The treatment protocol for LSIL is based on surveillance (Stoler et al., 2014).

\section{HSIL}

In HSIL, there are hyperchromatic atypical cells with loss of maturation and large nuclei affecting more than $1 / 3$ of the epithelium (Figure 1). Mitosis has reached the upper layers of the epithelium and atypical mitosis may be observed. There is strong staining with P16 (Figure 2 and 3). According to histomorphological appearance, it may be typed as:

-Thin HSIL (less than 10 cell thickness)

-Keratinized HSIL (abnormal keratinization on the surface, dyskeratotic cells in the epithelium and atypia)

-Condylomatous HSIL (condyloma-like) (Darragh et al., 2013; Stoler et al., 2014).

HSIL treatment is applied with cryotherapy thermal ablation, LEEP or conization. It is important to fully remove the transformation zone (Darragh et al., 2013).



Figure 1. HSIL: dysplasia of more than $1 / 2$ of epithelium(arow) (H\&E, X20).

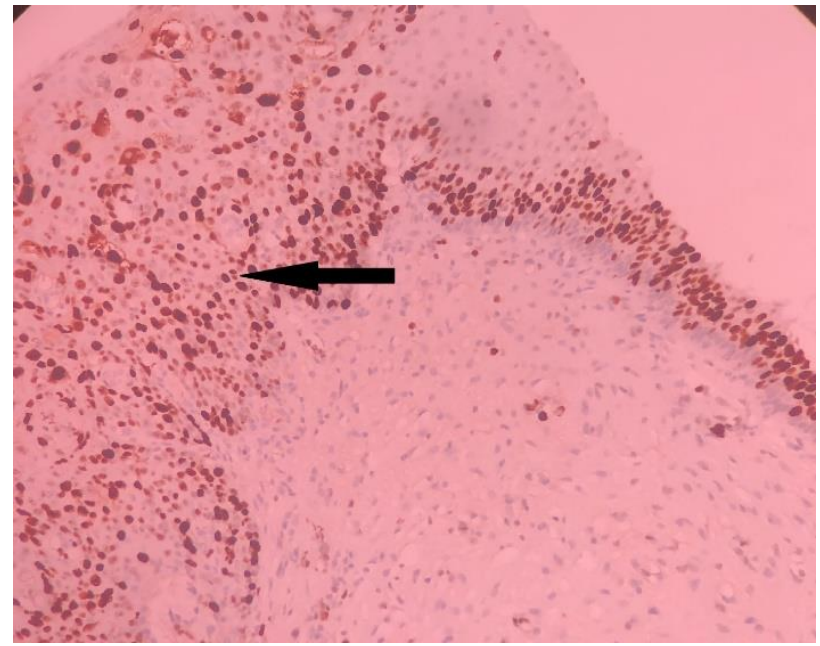

Figure 2. HSIL; Ki 67 immunohistochemical staining increases throughout full epitelium (arrow) (X20).



Figure 3. HSIL; p16 immunohistochemical study (long arrow). Normal epithelium is observed on the right side of the figure (short arrow) (X20).

\section{Differential Diagnosis}

Precancerous lesions of the cervix are frequently encountered in routine biopsies, but differential diagnosis of cases may be difficult. Basal cell hyperplasia, atrophy, reactive and repair-linked atypia and immature squamous metaplasia may mimic precancerous lesions.

In atrophy, maturation loss linked to hormonal insufficiency may be observed in multilayered squamous epithelium. Atrophy may be observed as typical atrophy, partial maturation atrophy and postmenopausal squamous atypia. In typical atrophy, the epithelium is thin, and maturation of cells is completely lost. The nucleus/cytoplasm ratio is increased; however, it is uniform, and mitosis is rare. Postmenopausal squamous atypia involves perinuclear cytoplasmic clarifying (pseudokoilocytosis), nuclear hyperchromasia, mild nuclear enlargement (up to two times) and double 
nuclei; however, chromatin distribution is normal. Atrophy with partial maturation observed has cells with large dark nuclei containing cytoplasmic glycogen, with rare mitosis (Wright \&Ferenczy 2001; Malpica\&Eucher, 2009). In situations where SIL cannot be differentiated with hematoxylin eosin, immunohistochemical studies may be beneficial. Ki-67 only stains parabasal cells in atrophic epithelium, while p16 is negative (Keating et al., 2001).

Basal cell hyperplasia is characterized by basal and parabasal thickness increases. The cell nuclei have large oval shapes and display vertical arrangement. Pleomorphism and hyperchromasia are not observed, with normal maturation of cells in the upper layers; however, in basal cells the typical "fence-like" arrangement is lost. Basal cell hyperplasia may be observed reactively in pregnancy, repair and inflammation (Wright \&Ferenczy, 2001).

Reactive and repair atypia may be specific or non-specific with acute or chronic infections. Reactive changes include mild enlargement of the nucleus and hyperchromasia. In some cases, prominent atypia may be observed; however, mitosis is rare. Spongious presence may be helpful for differentiation. In some reactive cases, there may be intermittent Ki-67 staining in the upper two thirds of the epithelium; however, p16 is negative (Keating et al., 2001).

LSIL may be mimicked by squamous papilloma. Squamous papilloma does not involve koilocytosis and has fibrovascular cores in the center which is not typical of condyloma (Stoler\&Schiffman, 2001).

It may be difficult to distinguish HSIL in situations with immature squamous metaplasia and atrophy and confusion may occur. In these situations, there are high nucleus/cytoplasm ratios in cells; however, in squamous metaplasia and atrophy, contour irregularity of the nucleus membrane is not observed. Mitotic figures may be observed in the basal layer; however, they are not observed in the upper half. For undecided cases, immunohistochemical staining with p16 is beneficial (Stoler et al., 2014). In some cases where definite diagnosis cannot be made due to reasons such as section errors, small sample pieces and cautery artifacts, there may be indecision between LSIL and HSIL and these cases may be called unidentified-grade SIL.

\section{Conclusion}

Cervical biopsies are common in routine practice. Hovewer, there are sometimes diagnostic difficulties. It is important to distinguish between HSIL and LSIL due to differences in treatment. Although histomorphology is gold standard, P16 and Ki-67 are beneficial immunohistochemical ancillary testes. However, it should be kept in mind that p16 can be positive in LSIL, and negative in HSIL.

Peer-review: Externally peer-reviewed.

Author Contributions: Concept-I. Ç. Design- I.

Ç. Supervision- I. Ç. Literature I. Ç. Review- I. Ç. Writing- I. Ç. Critical Review-IC.

Conflict of Interest: No conflict of interest was declared by the author.

Financial Disclosure: The author declared that this study hasn't received no financial support.

\section{Reference}

Cuschieri K, Wentzensen N. Human papillomavirus mRNA and p16 detection as biomarkers for the improved diagnosis of cervical neoplasia. Cancer Epidemiol Biomarkers Prev 2008;17: 253645.

Darragh TM, Colgan TJ, Thomas Cox J, Heller DS, Henry MR, Luff RD, et. al., Members of the LAST Project Work Groups. The Lower Anogenital Squamous Terminology Standardization project for HPV-associated lesions: background and consensus recommendations from the College of American Pathologists and the American Society for Colposcopy and Cervical Pathology. Int $\mathbf{J}$ Gynecol Pathol. 2013 Jan; 32 (1): 76-115. doi: 10.1097/PGP.0b013e31826916c7. Erratum in: Int J Gynecol Pathol. 2013 Jul; 32 (4): 432. Int J Gynecol Pathol. 2013 Mar; 32 (2): 241.

Doorbar J, Quint W, Banks L, Bravo IG, Stoler M, Broker TR, etl al. The biology and life-cycle of human papilloma viruses. Vaccine. $2012 \mathrm{Nov}$ 20; 30 Suppl 5: F55-70.

Edebal Z, Akıncıoğlu E, Kiseli M. Reproducibility of Diagnosis of ASC-US, Reflection of Diagnostic Criteria to Cervical Histopathological Results and Investigation of p16 Antibodies in Cervical Biopsies. Acta oncologica turcica. 2017; 50 (1): 50-55.

Eser SY, Cancer Incidence in Turkey. Karakoc H. Tuncer M (Editor). In: Cancer Control in Turkey, 1. Edition, Ankara, 776, 2010; 35-50. 
Ferlay J, Soerjomataram I, Dikshit R, Eser S, Mathers C, Rebelo M, et. al. Cancer incidence and mortality worldwide: source, methods and major patterns in GLOBOCAN 2012. Int $\mathrm{J}$ Cancer, 2015 Mar 1;136 (5): E 359-86).

Gupta M, Basavaraj PK. Histopathological Spectrum of Premalignant and Malignant Lesions of Uterine Cervix. National Journal of Laboratory Medicine. 2018 Jan, Vol-7(1): PO19-PO26.

Gustinucci D, Passamonti B, Cesarini E, Butera D, Palmieri EA, Bulletti S, et. al. Role of p16 (INK4a) cytology testing as an adjunct to enhance the diagnostic specificity and accuracy in human papillomavirus positive women within an organized cervical cancer screening program. Acta Cytol 2012; 56: 506-14.

Katki HA, Schiffman M, Castle PE, Fetterman B, Poitras NE, Lorey T, et al. Benchmarking CIN $3+$ risk as the basis for incorporating HPV and Pap cotesting into cervical screening and management guidelines. J Low Genit Tract Dis. 2013;17: S28-35.

Keating JT, Cviko A, Riethdorf S, Riethdorf L Quade BJ, Sun D, et. al., Crum CP. Ki-67, cyclin E, and p16INK4 are complimentary surrogate biomarkers for human papilloma virus-related cervical neoplasia. Am J SurgPathol. 2001 Jul;25(7):884-91.

Koss LG, Durfee GR. Unusual patterns of squamous epithelium of the uterine cervix: cytologic and pathologic study of koilocytotic atypia. Ann NY Acad sci.1956 Mar 30;63(6):1245-61.

Malpica A, Eucher E. Squomouse lesion of cervix. In: Biopsy interpretation of the uterin cervix and corpus. Wolters kluver,2th edition:2009:16-48.

Moore G, Fetterman B, Cox JT, Poitras N, Lorey T, Kinney W, et. al. Lessons from practice: risk of CIN 3 or cancer associated with an LSIL or HPV-positive ASC-US screening result in women aged 21 to 24 . Low Genit Tract Dis. 2010 Apr; 14 (2): 97-102.

Nayar R, Wilbur DC. The Pap Test and Bethesda 2014. "The reports of my demise have been greatly exaggerated." (after a quotation from Mark Twain). Actacytol. 2015; 59 (2): 121-32.

Ostor AG. Natural history of cervical intraepithelial neoplasia: a critical review. Int J Gynecol Pathol 1993; 12: 186-92.

Quint KD, de Koning MN, van Doorn LJ, Quint WG, Pirog EC. HPV genotyping and HPV16 variant analysis in glandular and squamous neoplastic lesions of the uterine cervix. Gnecol oncol.2010 May;117(2):297-301.
Saslow D, Solomon D, Lawson HW, Killackey M, Kulasingam SL, Cain J, et. al. American Cancer Society; American Society for Colposcopy and Cervical Pathology; American Society for Clinical Pathology. American Cancer Society, American Society for Colposcopy and Cervical Pathology and American Society for Clinical Pathology screening guidelines for the prevention and early detection of cervical cancer. Am J ClinPathol. 2012 Apr;137(4):51642

Sencan I, Keskinkilic B. TC. Ministry of Health. Turkey Cancer Statistics. //hsgm. saglık.gov.tr. Ankara 2017:20

Stoler M, Bergeron C, Colgan TJ, Ferenvzy AS, Herrington CS, Kim KR, et. al., Skuamous cell tumors and precursors,in Kurman RJ,ed: WHO Classification of Tumors of Female Reproductive organs. $4^{\text {th }}$ edition, Lyon, 2014 :172-182.

Stoler MH, Schiffman M. Interobserver reproducibility of cervical cytologic and histologic interpretations: realistic estimates from the ASCUS-LSIL Triage Study. JAMA 2001; 285: 1500-1505.

Stoler MH. Human papilloma viruses and cervical neoplasia:a model for carcinogenesis.Int J GynecolPathol. 2000 Jan;19 (1):16-28.

Sun M, Shen Y, Ren ML, Dong YM. Meta-analysis on the performance of p16/Ki67 dual immunostaining in detecting highgrade cervical intraepithelial neoplasm. J Cancer Res Ther. 2018 Sep;14 (Supplement): S587-S593. doi: 10.4103/0973-1482.183216.

Tsoumpou I, Arbyn M, Kyrgiou M, Wentzensen N, Koliopoulos G, Martin-Hirsch P, et. al. p16INK4a immunostaining in cytological and histological specimens from the uterine cervix: a systematic review and meta-analysis. Cancer Treat Rev. 2009; 35 (3): 210-20.

Voltaggio L, Cimino-Mathews A, Bishop JA, Argani P, Cuda JD, Epstein JI, et. al. Current concepts in the diagnosis and pathobiology of intraepithelial neoplasia: A review by organ system. CA Cancer J Clin. 2016 Sep; 66 (5): 408-36. 
Walboomers JM, Jacobs MV, Manos MM, Bosch FX, Kummer JA, Shah KV, Snijders PJ, Peto J, Meijer CJ, Muñoz N. Human papillomavirus is a necessary cause of invasive cervical cancer worldwide. J Pathol. 1999;189 (1):12-19.

Wentzensen N, von Knebel Doeberitz M. Biomarkers in cervical cancer screening. Dis Markers. 2007; 23 (4): 315-30.

Wright TC, Ferenczy A. Benign disease of the cervix. in: Kurman RJ, ed. Blaustein's pathology of the female genital tract. Newyork: SpringerVerlag; 2001:225-252. 